\title{
Constellation Deployment for the FORMOSAT-3/COSMIC Mission
}

\author{
Chen-Joe Fong, Member, IEEE, Wen-Tzong Shiau, Chen-Tsung Lin, Tien-Chuan Kuo, \\ Chung-Huei Chu, Shan-Kuo Yang, Nick L. Yen, Shao-Shing Chen, Ying-Hwa Kuo, \\ Yuei-An Liou, Senior Member, IEEE, and Sien Chi
}

\begin{abstract}
The FORMOSA Satellite Series No. 3/Constellation Observing System for Meteorology, Ionosphere and Climate (FORMOSAT-3/COSMIC) spacecraft constellation consisting of six low-earth-orbiting satellites is the world's first operational Global Positioning System (GPS) radio occultation mission. The mission has been jointly developed by the National Space Organization of Taiwan and the University Corporation for Atmospheric Research of the U.S. in collaboration with the Jet Propulsion Laboratory, NASA, and the Naval Research Laboratory for three onboard payloads, including a GPS Occultation Receiver, a triband beacon, and a tiny ionospheric photometer. The FORMOSAT-3/COSMIC mission was successfully launched from Vandenberg into the same orbit plane of the designated 516-km circular parking orbit altitude on April 15, 2006. After the six satellites completed the in-orbit checkout activities, the mission was started immediately at the parking orbit for in-orbit checkout, calibration, and experiment of three onboard payloads. Individual spacecraft thrust burns for orbit raising were performed to begin the constellation deployment of the satellites into six separate orbit planes. All six FORMOSAT-3/COSMIC satellites are maintained in a good state of health except spacecraft flight model no. 2 , which has had power shortages. Five out of the six satellites had reached their final mission orbits of $800 \mathrm{~km}$ as of November 2007. This paper provides an overview of the constellation spacecraft design, constellation mission operations, constellation deployment timeline evolution, associated spacecraft mass property and moment of inertia results, orbit-raising challenges, and lessons learned during the orbit-raising operations.
\end{abstract}

Index Terms-Constellation deployment, Constellation Observing System for Meteorology, Ionosphere and Climate (COSMIC), FORMOSA Satellite Series No. 3 (FORMOSAT-3), geodesy, Global Positioning System (GPS) radio occultation (RO), satellite.

Manuscript received August 31, 2007; revised May 2, 2008. Current version published October 30, 2008.

C.-J. Fong is with the Systems Engineering Division, National Space Organization, Hsinchu 300, Taiwan, and also with the Department of Photonics and Institute of Electro-Optical Engineering, National Chiao Tung University, Hsinchu 300, Taiwan (e-mail: cjfong@nspo.org.tw).

W.-T. Shiau, C.-T. Lin, T.-C. Kuo, C.-H. Chu, S.-K. Yang, N. L. Yen, and S.-S. Chen are with the National Space Organization, Hsinchu 300, Taiwan.

Y.-H. Kuo is with the COSMIC Program, The University Corporation for Atmospheric Research, Boulder, CO 80307 USA (e-mail: kuo@ucar.edu).

Y.-A. Liou is with the Center for Space and Remote Sensing Research, National Central University, Chungli 320, Taiwan (e-mail: yueian@ csrsr.ncu. edu.tw).

S. Chi is with the Department of Photonics and Institute of ElectroOptical Engineering, National Chiao Tung University, Hsinchu 300, Taiwan, and also with the Department of Electrical Engineering, Yuan Ze University, Chungli 320, Taiwan (e-mail: schi@mail.nctu.edu.tw).

Color versions of one or more of the figures in this paper are available online at http://ieeexplore.ieee.org.

Digital Object Identifier 10.1109/TGRS.2008.2005202

\section{INTRODUCTION}

$\mathbf{T}$ HE MAIN idea of radio occultation (RO) scheme emerged in the early days of interplanetary flight [1]-[5]. It is well known that the limb sounding of the atmosphere and ionosphere using the RO technique can be performed with any two cooperating satellites. A few early RO experiments from a satellite-to-satellite tracking link had been conducted before the Global Positioning System (GPS) becomes operational. These included the radio link between GEOS-3 and ATS-6 [6] and between the Mir station and a geostationary satellite [7]. The GPS RO technique, which makes use of the radio signals transmitted by the GPS satellites, has emerged as a powerful approach for sounding the global atmosphere in all weather over both lands and oceans [8]-[11]. The GPS/meteorology (GPS/MET) experiment (in 1995-1997) showed that the GPS RO technique offers great advantages over the traditional passive microwave measurement of the atmosphere by satellites and became the first "proof-of-concept" RO mission to Earth [12]-[18]. The extraordinary success of GPS/MET mission had inspired a series of other RO missions, e.g., the Ørsted (in 1999), the SUNSAT (in 1999), the Satellite de Aplicaciones Cientificas-C (in 2001), the Challenging Minisatellite Payload (in 2001), and the twin Gravity Recovery and Climate Experiment missions (in 2002). The GPS RO sounding data have been shown to be of high accuracy and vertical resolution. All these missions set the stage for the birth of the FORMOSA Satellite Series No. 3/ Constellation Observing System for Meteorology, Ionosphere and Climate (FORMOSAT-3/COSMIC) mission [15]-[18].

The FORMOSAT-3/COSMIC mission is the world's first operational constellation system of six low-earth-orbiting (LEO) microsatellites assigned mainly for the GPS RO remote sensing of the atmosphere and ionosphere at various altitudes with global coverage. The primary scientific goal is to demonstrate the value of near-real-time GPS RO observation in operational numerical weather prediction. The mission provides about 2500 soundings per day in near-real-time vertical profiles of temperature, pressure, refractivity, and water vapor in neutral atmosphere, and electron density in the ionosphere [19]-[26]. In the near future, other Global Navigation Satellite Systems (GNSSs), such as the Russian GNSS and the planned European Galileo system, will be used to extend the region of applications by use of the GPS RO technique [27], [28].

The FORMOSAT-3/COSMIC mission was successfully launched from Vandenberg Air Force Base (VAFB) in California at 1:40 coordinated universal time (UTC) on April 15, 2006. The FORMOSAT-3/COSMIC mission is jointly 


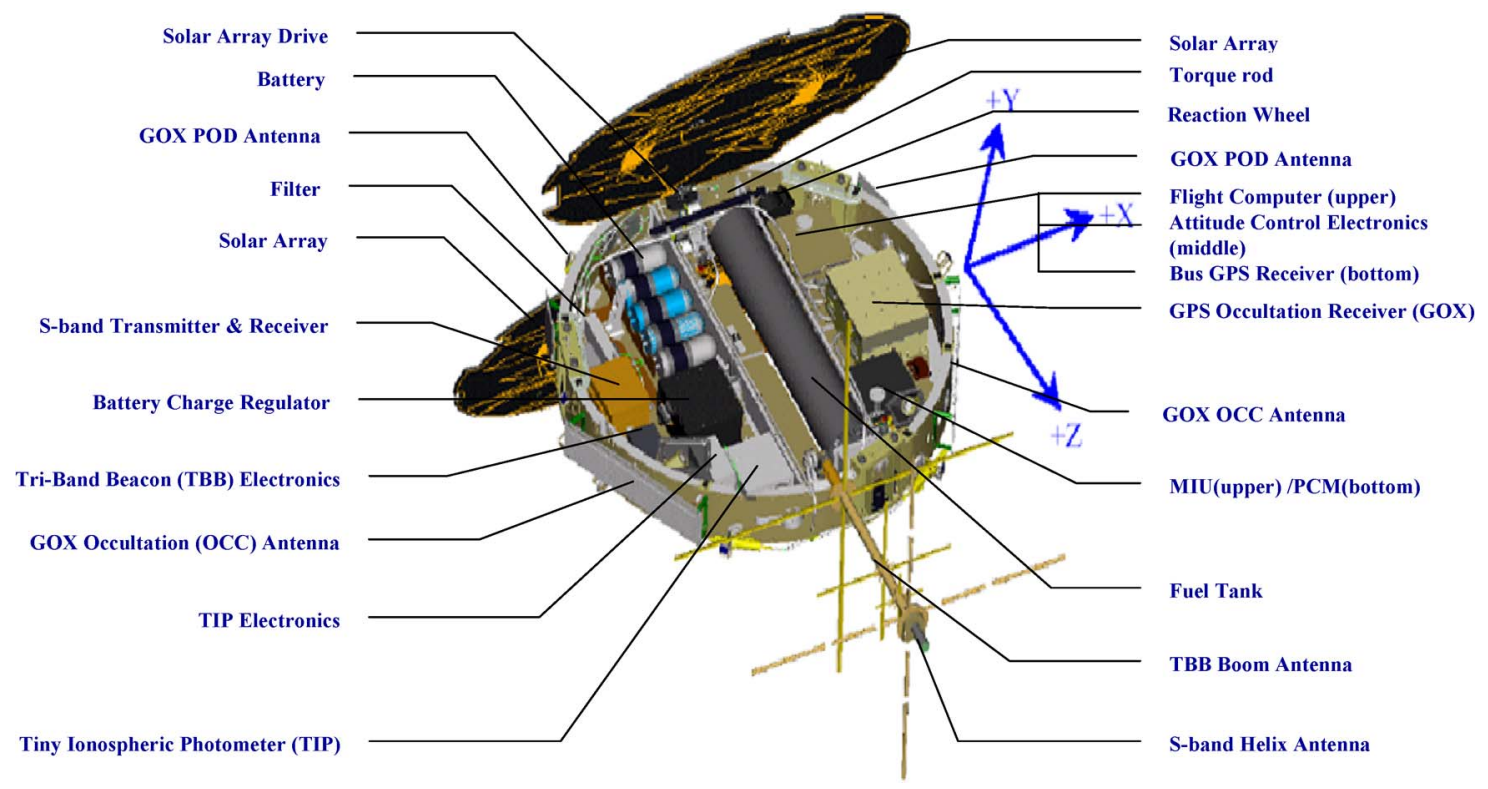

Fig. 1. FORMOSAT-3/COSMIC spacecraft main components.

developed by the National Space Organization (NSPO) and the University Corporation for Atmospheric Research (UCAR) in collaboration with the Orbital Sciences Corporation (OSC) for the satellite bus, the Jet Propulsion Laboratory (JPL), and the Naval Research Laboratory (NRL) for three onboard payloads, including GPS Occultation Receiver (GOX), triband beacon (TBB), and tiny ionospheric photometer (TIP). The TIP payload instrument is routinely collecting data at night and observes the equatorial anomaly arcs and other density anomalies through the measurements of $1356 \AA$ radiation. The nadir-pointing TBB enables observations of the line-of-sight total electron contents and scintillations along the radio links of the FORMOSAT-3/COSMIC-TBB ground stations. The data from these two instruments complement the ionospheric observations from the GOX and are used to improve the retrieval of electron density profiles at night and over TBB ground stations. These data are also valuable for the evaluation of ionospheric models and the use in space weather data assimilation systems [29]. The FORMOSAT-3/COSMIC mission preliminary results could be referenced to Cheng et al. [30], Liou et al. [31], Fong et al. [32]-[34], and Yen et al. [35]. In this paper, we present a new fundamental concept of the FORMOSAT-3/ COSMIC spacecraft constellation and flight dynamic design, constellation deployment plan, constellation mission operations, constellation deployment results, orbit-raising challenges, and lessons learned.

\section{SPaCECRAFt CONSTEllation AND Flight DYNAMICS DESIGN OVERVIEW}

The FORMOSAT-3/COSMIC mission takes advantage of nodal precession to conduct orbit-raising maneuvers at the appropriate times so that the effect of different altitudes makes the orbital planes drift. An overview of the spacecraft system, propulsion subsystem size, and the attitude control subsystem (ACS) design related to constellation deployment and ground flight dynamics design is described as follows [39], [41].
TABLE I

FORMOSAT-3 /COSMIC CONSTELLATION SPACECRAFT BUS KEY DESIGN

\begin{tabular}{|l|l|}
\hline Mass & $\sim 54 \mathrm{~kg}$ (Dry Weight) \\
\hline Power: & $\sim 81$ Watts (bus and payload) \\
\hline Shape & Disc-shape of 116cm diameter, 18cm in height \\
\hline Science Data Storage & $128 \mathrm{MB}$ \\
\hline Distributed Architecture & Motorola 68302 Microprocessor \\
\hline Attitude Control & $\begin{array}{l}\text { Magnetic 3-axis Control } \\
\text { Pointing Control }=5^{\circ} \text { Roll \& Yaw, 2 }{ }^{\circ} \text { Pitch }\end{array}$ \\
\hline Propulsion & Hydrazine Propulsion Subsystem \\
\hline S-Band Communications & $\begin{array}{l}\text { HDLC Command Uplink }(32 \mathrm{kbps}) \\
\text { CCSDS Telemetry Downlink }(2 \mathrm{Mbps})\end{array}$ \\
\hline Single String Bus & Constellation Redundancy \\
\hline
\end{tabular}

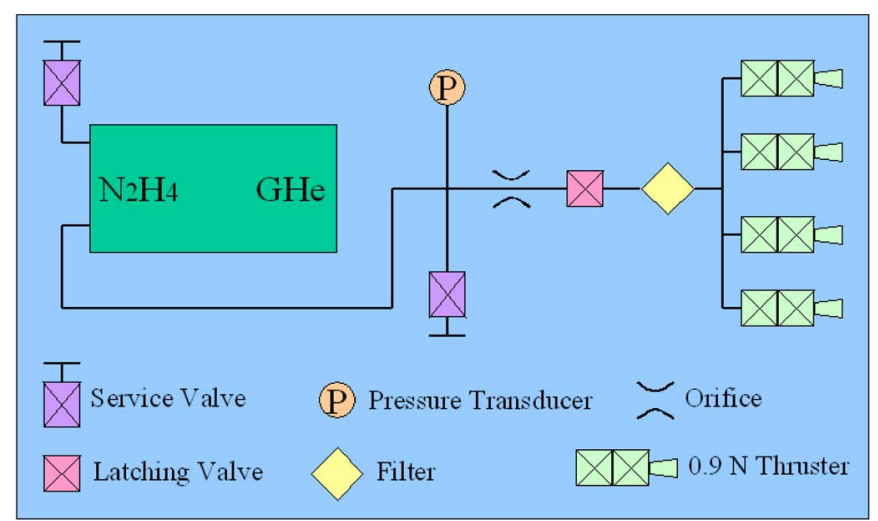

Fig. 2. Spacecraft RCS block diagram.

\section{A. Spacecraft System}

Fig. 1 shows the FORMOSAT-3/COSMIC spacecraft inflight configuration and its major components. The major subsystem elements of the spacecraft system are payload, structure and mechanism, thermal control, electrical power, command and data handling, and radio frequency communication subsystems; reaction control subsystem (RCS); ACS; and flight software subsystem. The spacecraft bus provides structure, RF power, electrical power, thermal control, attitude control, orbit raising, and data support to the instrument [34], [35], [39]-[41]. 
Thruster Geometry

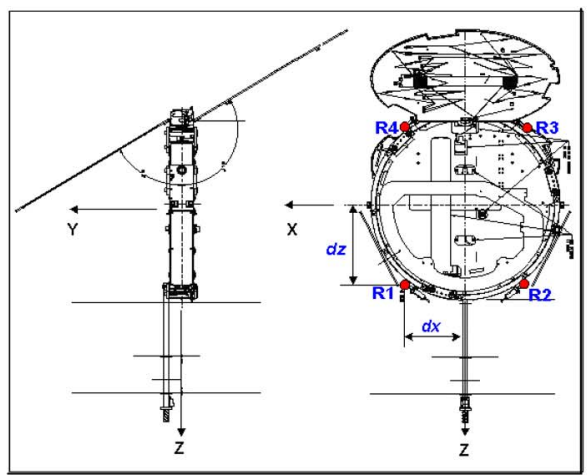

Torque Generation

\begin{tabular}{|c|c|}
\hline Torque Direction & Thruster Combination \\
\hline$+\mathrm{X}$ & $\mathrm{R} 3$ \& $\mathrm{R} 4$ \\
\hline$-\mathrm{X}$ & $\mathrm{R} 1$ \& 2 \\
\hline$+\mathrm{Y}$ & $\mathrm{R} 2$ \& $\mathrm{R} 4$ \\
\hline$-\mathrm{Y}$ & $\mathrm{R} 1$ \& 3 \\
\hline$+\mathrm{Z}$ & $\mathrm{R} 1$ \& $\mathrm{R} 4$ \\
\hline$-\mathrm{Z}$ & $\mathrm{R} 2 \& \mathrm{R} 3$ \\
\hline
\end{tabular}

Thruster Data:

- 15 msec min. Turn-On time

- 0.2 lbf (BOL), 5:1 Blowdown

Fig. 3. RCS thruster geometry and torque.

Table I shows the FORMOSAT-3/COSMIC constellation spacecraft bus key design features.

\section{B. Spacecraft Propulsion for Thrust Burn}

The spacecraft propulsion subsystem (also named as the RCS $)$ is a blowdown monopropellant hydrazine $\left(\mathrm{N}_{2} \mathrm{H}_{4}\right)$ propulsion subsystem with gaseous helium $(\mathrm{GHe})$ as the pressurant. The designed blowdown ratio is $5: 1$ with a maximum expected operating pressure of $400 \mathrm{psia}$ at $50^{\circ} \mathrm{C}$. The initial tank pressure is pressurized to about $330 \mathrm{psia}$ at $20^{\circ} \mathrm{C}$. The RCS is utilized to provide impulses for attitude control during orbit raising and to transfer the satellite from the injection orbit to an intermediate orbit if required and, finally, to the mission orbit of the constellation. Fig. 2 shows the block diagram of the RCS. The FORMOSAT-3/COSMIC RCS consists of a propellant tank, gaseous helium and hydrazine service valves, a latching valve, a filter, an orifice, four thrusters, pressure transducer, and a set of pipelines. The spacecraft RCS characteristics are summarized as follows [37], [41]:

1) thrust force: 1.1 [beginning of life (BOL)] $-0.2 \mathrm{~N}$ [end of life (EOL)];

2) specific impulse: $217-194 \mathrm{~s}$;

3) propellant mass: $\sim 6.65 \mathrm{~kg}$;

4) thrust type: OFF pulsing (duty cycle $\leqq 50 \%$ ).

Fig. 3 shows the locations of the four thrusters (R1, R2, R3, and $\mathrm{R} 4$ ), which are located in the four quadrants of the $x-z$ plane of

\section{Cant (109) Enables 3-Axis Control}

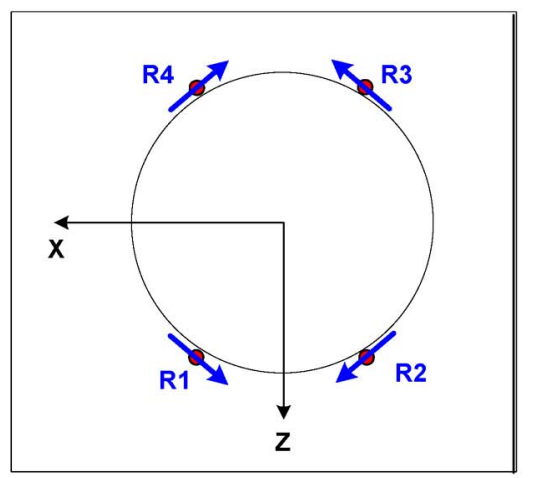

\section{Flight Configuration}

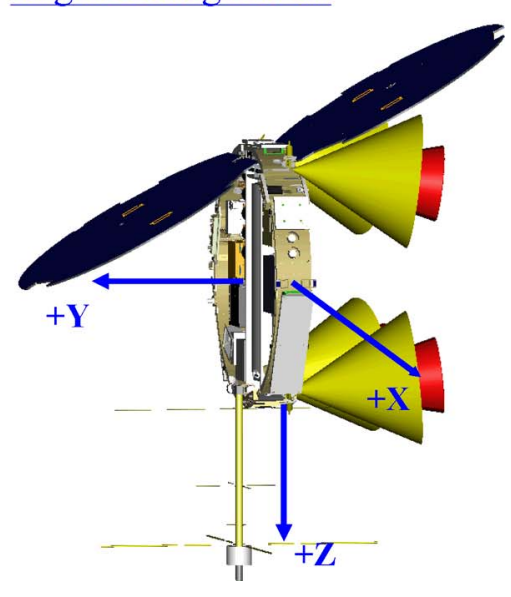

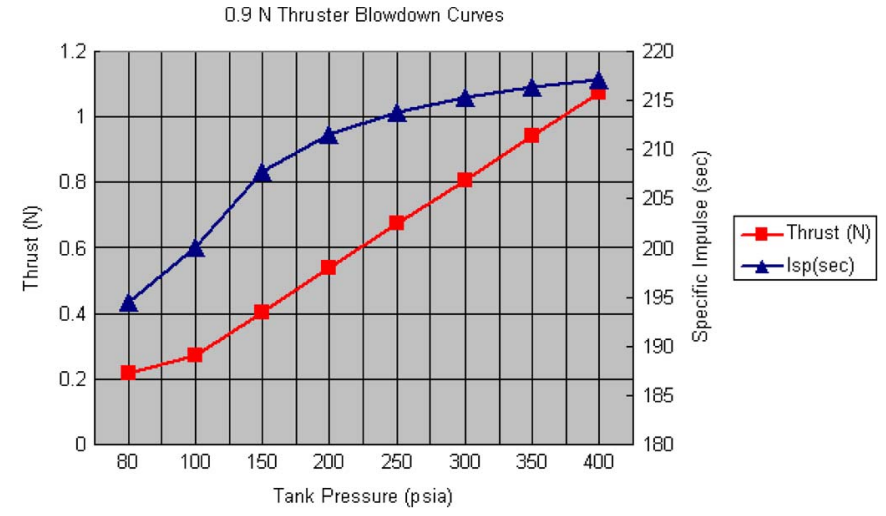

Fig. 4. RCS blowdown curve.

the satellites. These four thrusters are canted by $10^{\circ}$ to enable three-axis control capability. By modulating the off-pulsing duration of the four thrusters, control torque is generated for the attitude control around $X, Y$, and $Z$ axes of the satellite. The estimated thrust and specific impulse over the entire blowdown pressure range are shown in Fig. 4.

\section{Spacecraft Attitude Control for Constellation Deployment}

The function of the spacecraft ACS is to control the attitude of the satellite in the safe, stabilization, nadir, nadir-yaw, and thrust modes. The sensors for attitude estimation include earth horizon sensors, coarse sun sensors, and a magnetometer. The 


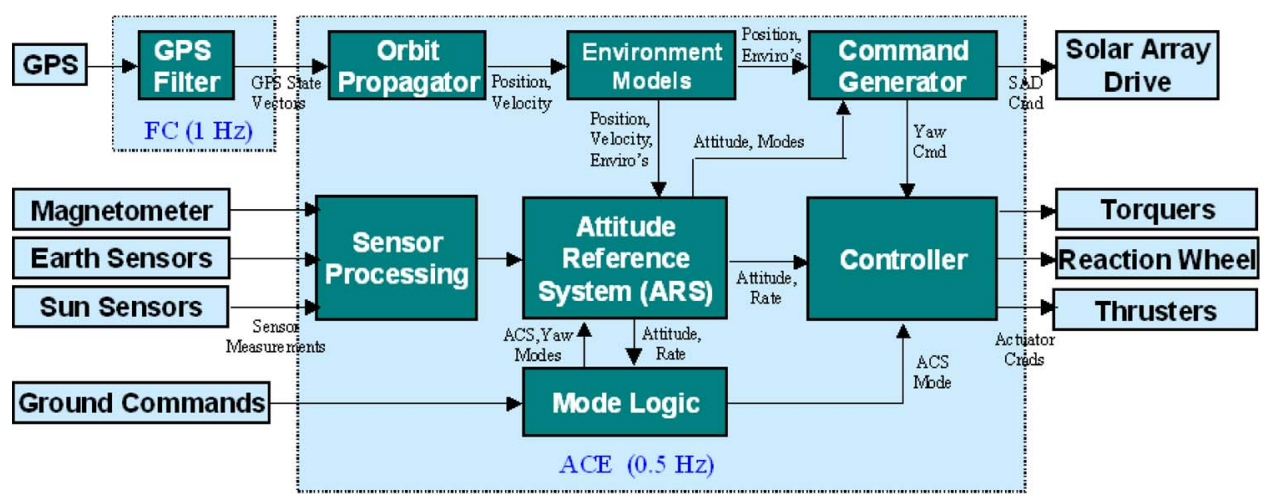

Fig. 5. Functional block diagram of the spacecraft ACS.

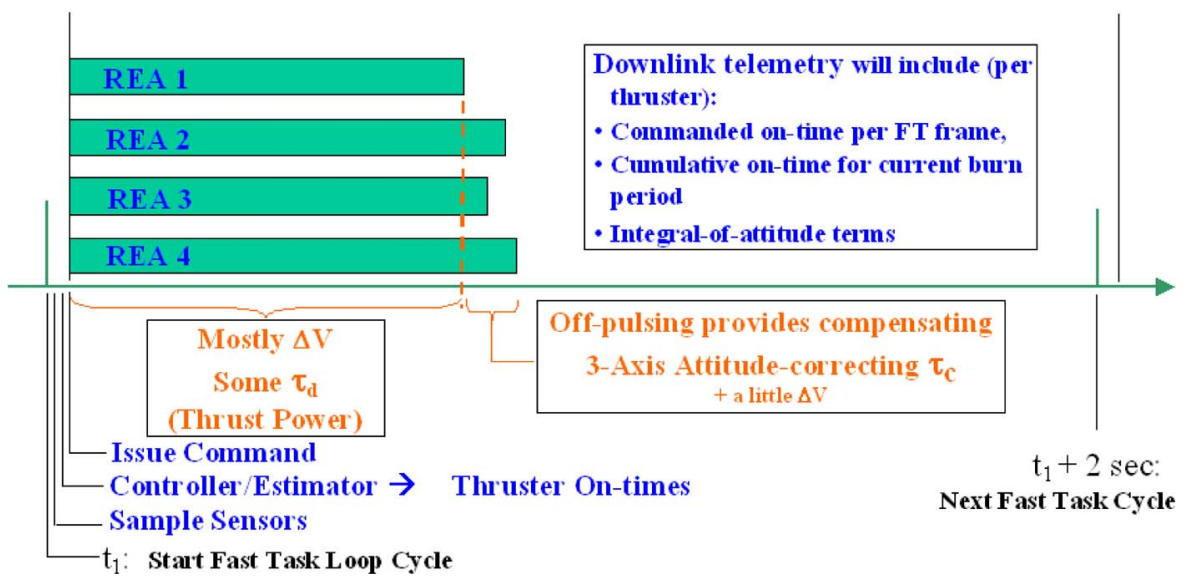

Fig. 6. Off-pulsing concept of ACS thrust mode.

actuators for attitude control include magnetic torquers, a reaction wheel, and thrusters [37], [41].

Fig. 5 shows the functional block diagram of the spacecraft ACS, where FC stands for flight computer and ACE means the attitude control electronics. In Fig. 5, the Attitude Reference System (ARS) includes attitude and rate estimators using a Kalman filter algorithm with measurements from the sensors. The ACS controller processes the attitude and rate estimation from ARS through the control gains/algorithm and distributes the torque commands to the actuators. The ACS also receives the satellite position and velocity data from the bus GPS receiver. Based on this information, it then propagates and computes necessary information for the navigation purpose, the ARS, and the commanded angles for the solar array drive (SAD).

The thrust mode is dedicated to the orbit-raising operation. When the orbit-raising operation is performed, the satellite first maneuvers itself to a yaw angle of $90^{\circ}$ to align the thrust direction with the velocity direction. Then, as soon as the ACS enters the thrust mode, the thruster ignition starts up, and the attitude is controlled by the thrusters while orbit raising proceeds. When the operation is terminated or finished, the ACS enters the nadir-yaw mode and maneuvers itself to a preset yaw angle.

A proportional-integral-derivative (PID) controller is designed for the thrust mode to compute the desired three-axis control torque. Four thrusters are commanded, off-pulsing in each control cycle to provide both the impulse for orbit raising and the three-axis control torque to diminish the attitude errors. Fig. 6 shows the concept of the "off pulsing" in each control cycle. In orbit-raising operations, the thrust turn-on time in each control cycle is either kept constant as the "InitialThurstPower" value or increased by "AddThrustIncrement" seconds in every "AddThrustInterval" control cycles. The thrust mode control gains are adjusted in order to compensate for the changes in thrust level during the RCS blowdown process.

The PID controller will minimize the attitude control error and improve the orbit-raising performance, but it suffers from the relative instability issue. This is because the control system may diverge with a large thruster turn-on time when the PID integral terms are not yet converged to their steady-state values. Therefore, during orbit-raising operations, the PID controller requires a series of "calibration burns" in order to converge the attitude integral terms and to ramp up the thruster turn-on time to a larger value. Calibration burn is usually a smaller burn than the full-thrust burn. During the calibration process, the final values of the thrust turn-on time and the integral terms of a previous burn are used as the initial values for the next burn. In this way, it takes about six to eight calibration burns to reach the so-called full-thrust burn.

\section{FDF and Orbit Dynamics}

The main function of ground-based Flight Dynamics Facility (FDF) is to conduct various orbit dynamics analyses, including orbit determination, orbit-ephemeris propagation, 
orbit-maneuver planning, orbit-parameter trending, and orbitevent prediction. In the FORMOSAT-3/COSMIC mission, we use the commercial off-the-shelf software package called "Orbit Analysis System (OASYS)" in FDF for orbit analysis. The OASYS database includes the thrusting model of the onboard RCS and ACS, such as the thruster number, location, and direction; propellant mass and pressure; pressurant mass; blowdown curves for thrust and specific impulse; and thrust type, thruster duty cycle, and efficiency [36], [40].

The blowdown curves for thrust force $(F)$ and specific impulse $\left(I_{\mathrm{sp}}\right)$, as shown in Fig. 4, are modeled as follows:

$$
\begin{aligned}
F & =\left(0.001141+0.0006^{*} P\right)^{*} 4.448221(\text { in newtons }) \\
I_{\mathrm{sp}} & =222.84-2268.4 / P(\text { in seconds })
\end{aligned}
$$

where

$F \quad$ the thrust force;

$I_{\mathrm{sp}} \quad$ the specific impulse;

$P \quad$ the propellant mass.

and used in the OASYS database for FORMOSAT-3/COSMIC orbit raising. Both equations are functions of the propellant tank pressure in the unit of psia.

The thrust power in each ACS control cycle is modeled as the duty cycle of the thruster and listed as Duty Cycle = Thrust Power/Control Cycle. In full-thrust orbit-raising burns, the thrust power in each control cycle is kept constant, as the duty cycle is in the OASYS model. However, in calibration burns, the thrust power in each control cycle is linearly ramped up to the end of the burn. In other words, the duty cycle in each control cycle also increases in the same way as the thrust power does. Unfortunately, there is no way in OASYS to correctly model the calibration burns with increasing thrust powers. Instead, an averaged thrust power (duty cycle) using the initial and final thrust powers of the burn is used in the OASYS database to model the thrusting of a calibration burn.

The OASYS is also used to conduct an orbit determination to compare the actual postburn orbit and the OASYS-planned postburn orbit after a thrust burn is completed. Based on the actual and OASYS-planned orbit altitudes, a thrusting efficiency is recalculated, which, in turn, provides another input for the next orbit-raising planning.

\section{Constellation Deployment Plan}

The FORMOSAT-3/COSMIC constellation deployment concept was to launch the entire cluster of satellites by a single launch vehicle. All six satellites were delivered to the same injection orbit plane of the designated $516-\mathrm{km}$ circular parking orbit altitude, and they were in a cluster formation fly configuration after separation from the launch vehicle. Next, the six satellites were deployed into six different orbit planes at specific time intervals using the nodal precession method. In this method, the differences in the spacecraft orbit heights allow them to precess at different rates, thus separating the orbit planes [36], [37].

The nodal precession is a well-known gravity phenomenon, where the orbital plane drifts due to the oblateness of the
Earth [36], [37]. The approach using the natural physics of the oblateness of the Earth, as well as time, allows the spacecraft to drift instead of requiring complex propulsion systems or even depending on individual launch vehicle to arrive at their orbit planes directly. Although this approach requires a lengthy orbit-deployment time, it significantly reduces the size of the propulsion subsystem design. The evolution of the constellation plan and the constellation deployment principle are described as follows.

\section{A. Original Constellation Deployment Plan}

The FORMOSAT-3/COSMIC mission operation plan changes as time passes, following launch. Originally, the FORMOSAT-3 constellation deployment plan included a tandem flight design during the deployment phase. The tandem flight satellites would maintain an along-track distance of 200-400 km. Two pairs [flight model no.1 (FM1) and FM2; FM3 and FM4] of satellites would fly in tandem in an intermediate orbit altitude (525 and $576 \mathrm{~km}$ ) for the geodesy research [27]. However, spacecraft FM3 and FM4 have been very close together since the launch of the satellites. The data from April to October were able to provide adequate data for geodesy research at the parking orbit of $516 \mathrm{~km}$. The constellation plan was thus changed to meet the need for more science dumps for intensive operation period campaign and tropical cyclone (typhoon, hurricane, etc.) prediction forecast studies [31]-[35].

The constellation plan at an $800-\mathrm{km}$ orbit with $24^{\circ}$ separation planes was for a shorter deployment time consideration (13 months after launch) and based on the assumption that spacecraft attitude control performance in lower altitude is worse than that in the mission orbit. However, this plan is not favorable for the ionospheric monitoring and climate seasonal variability studies due to nonuniform coverage globally. Shorter duration to complete the constellation deployment has become less of a concern since the spacecraft attitude performance is better than expected, and the data of the early phase (mostly at lower orbit) are much better than anticipated [36], [40].

\section{B. New Constellation Deployment Plan}

Scientists from Taiwan and the U.S. coherently favor $30^{\circ}$ separation with approximately six months longer constellation deployment duration over $24^{\circ}$ separation for global uniform coverage in local solar time. The original constellation mission operation plan was revised, manpower was reallocated, and the orbit-raising schedule was rearranged to accommodate the science team's request. This change in new constellation plan reflects integral teamwork among the operation team and data users and leads to greater mission success. The constellation deployment plan change from $24^{\circ}$ to $30^{\circ}$ separation was made in September 2006 after the completion of FM5 orbit transfer and during FM2 orbit raising. The decision was made to put the FM2 orbit transfer on hold in October 2006 and to allow its separation from FM5 further. The decision postponed the completion of the final constellation to December 2007 [40], [41]. 


\section{Constellation Deployment Principle}

The technical principles relevant to perform the constellation deployment related to Earth oblateness and right ascension ascending node (RAAN) phasing, argument of latitude (AOL) final phasing and contact conflict avoidance, and dispersion operation are described as follows [36], [37], [40], [41].

1) Earth Oblateness and RAAN Phasing: The total mass of a FORMOSAT-3 satellite is $61.05 \mathrm{~kg}$, including the dry mass of $54.4 \mathrm{~kg}$ and the propellant mass of $6.65 \mathrm{~kg}$. The overall altitude increase from injection orbit to mission orbit is $285 \mathrm{~km}$. The estimated total delta- $V$ required is $147 \mathrm{~m} / \mathrm{s}$, and the estimated propellant required is $4.6 \mathrm{~kg}$. Fuel margin is $2.05 \mathrm{~kg}$ [36], [37], [40], [41].

Due to the oblateness of the Earth gravity, the RAAN of a LEO satellite will drift away at a rate, which is a function of the semimajor axis (SMA), inclination, and eccentricity of the orbit. The drift rate of RAAN $(\Delta \Omega / \Delta t)$, also called "orbit precession rate," is modeled as follows for the FORMOSAT-3 near-circular orbit with an inclination of $72^{\circ}$ and an eccentricity of zero [44]

$$
\Delta \Omega \cong-6.3804 \times 10^{13} \Delta\left(a^{-7 / 2}\right) \cdot \Delta t
$$

where

$\Delta \Omega$ the drift of the RAAN after a deployment time of $\Delta t$; $a$ the SMA of the orbit altitude in kilometers;

$\Delta t \quad$ the deployment time period in days.

The deployment strategy is to use the first raised spacecraft (FM5) as a reference point. The second spacecraft is then raised to its mission orbit when the difference of the RAAN between the first and the second spacecraft reaches the desired separation angle. The third spacecraft was then raised when the difference of the RAAN between the first and third spacecraft reaches the value of twice of the planned separation angle and so forth.

2) AOL Final Phasing and Contact Conflict Avoidance: As one ground station can support one pass from an elevation angle of $10^{\circ}$ to $10^{\circ}$, if there are two satellites flying over the same ground station at the same time frame, the ground station could support only one satellite unless there were special arrangements. Therefore, a $52.5^{\circ}$ phasing on AOL must be implemented to ensure that one orbit's worth of occultation science data are sent to the receiving stations. Among the six mission orbits of the FORMOSAT-3 constellation, the maximal difference in SMA ( $\Delta a$ in meters) and the maximal deviation $(\Delta L$ in degrees) of the AOL from its nominal value are deployed to fulfill the following equation so that multiple contacts at the same ground station at the same time are avoided [40], [41]:

$$
\Delta a+5^{*} \Delta L<50 \text {. }
$$

The differentiation of the AOLs of the other five satellites against the reference orbit is achieved by controlling the altitude deployment profile in the final stage of the "maneuvering window." When the orbit altitude is different from the reference orbit (FM5), the AOL change rate is also different from the reference orbit. The different AOL change rate differentiates the AOL of the satellite against the reference orbit along with time. By manipulating the altitude deployment profile in the final stage, the AOL difference is targeted at the same time to

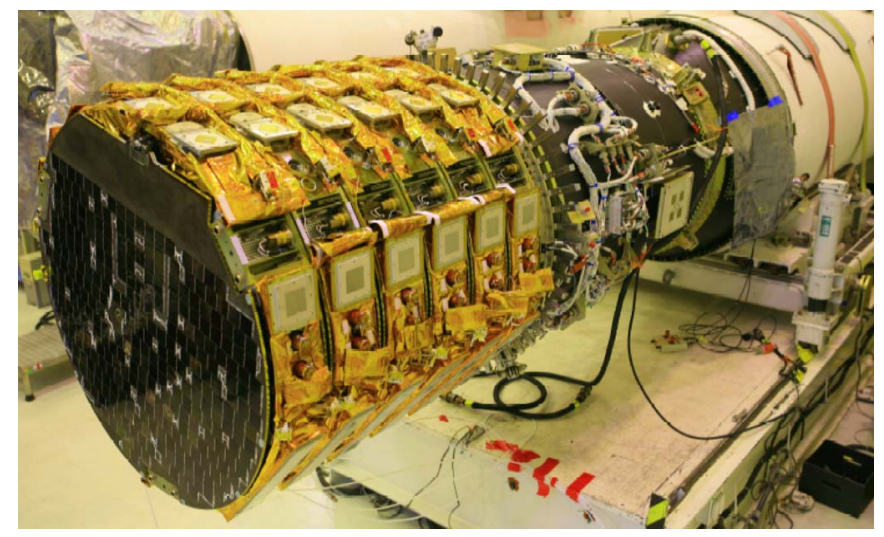

Fig. 7. Six FORMOSAT-3/COSMIC satellites in stowed configuration and stacked on the Minotaur launch vehicle.

maneuver the satellite into the mission orbit altitude. Then, both the RAAN and AOL differences are frozen and kept constant simultaneously.

3) Spacecraft Dispersion Operation to Increase Science Data Downloads: The dispersion operation is very similar to the AOL phasing. In order to increase the number of GOX data downlink, a spacecraft dispersion operation plan was executed to differentiate the AOLs of FM4, FM3, FM1, and FM6 in parking orbits. These four satellites were maneuvered to the same altitude around $519 \mathrm{~km}$ with an AOL difference of around $80^{\circ}$ so that they can contact a ground station in turn to increase GOX science data downlink with no contact conflicts [36]-[38].

\section{Constellation Mission Operations}

The FORMOSAT-3/COSMIC constellation mission operations are divided into four phases: Phase $\mathrm{I}$ is the Launch and Early Orbit (L\&EO) phase; phase II is the constellation deployment phase; phase III is the final constellation phase; and phase IV is the extended mission phase. Phase I includes launch, separation, ground initial acquisition, spacecraft bus checkout, and payload checkout. During phase II, the spacecraft are raised to the final mission orbit heights by means of nodal precession. The science mission is conducted already during phase II when there is no thrust burn. All spacecraft should reach their final orbits with the designed RAAN and AOL at phase III, and all science experiments are conducted continuously when there is no burn activity. The duration of phase IV is three years, commencing with the completion of phase III [35]-[40].

\section{A. Launch and Injection Orbits}

Fig. 7 shows a photograph of six satellites in stowed configuration and stacked on the Minotaur launch vehicle at the VAFB launch site. After successful launch, the FORMOSAT-3/ COSMIC constellation has the following orbit characteristics [36], [37]:

1) SMA: $6893 \mathrm{~km}$;

2) eccentricity $(E): 0.00323$;

3) inclination $(I): 71.992^{\circ}$;

4) RAAN $\Omega: 301.158^{\circ}$. 


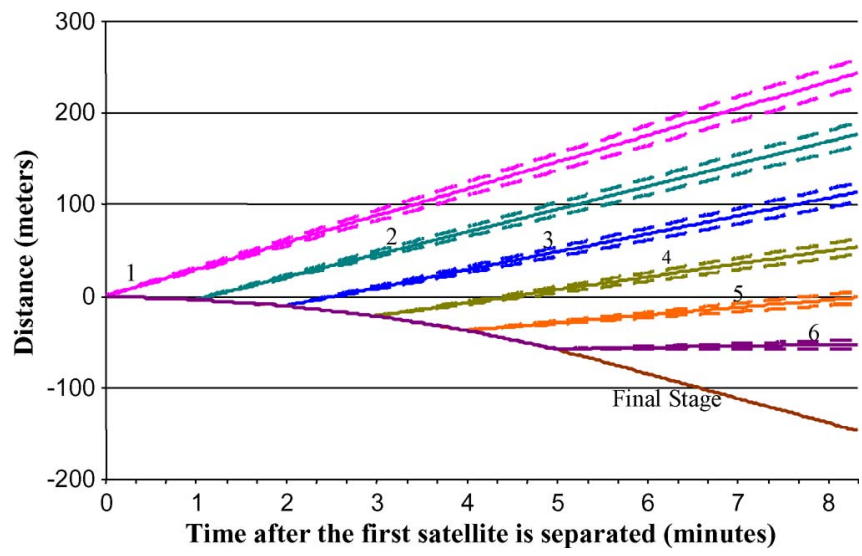

Fig. 8. Resulting spacecraft separation simulation result.

The six identical satellites are deployed into six mission orbits with the following orbit characteristics for $i=1 \sim 6$ :

1) $\operatorname{SMA}\left(\mathrm{SMA}_{i}\right): 7178 \mathrm{~km}$;

2) eccentricity $\left(E_{i}\right):<0.014$;

3) inclination $\left(I_{i}\right): 71.992^{\circ}$;

4) $\operatorname{RAAN}\left(\Omega_{i}\right): \Omega_{5},\left(\Omega_{5}-30^{\circ}\right),\left(\Omega_{5}-60^{\circ}\right),\left(\Omega_{5}-90^{\circ}\right)$, $\left(\Omega_{5}-120^{\circ}\right)$, and $\left(\Omega_{5}-150^{\circ}\right) \pm 5^{\circ}$;

5) $\left(\mathrm{AOL}, L_{i}\right): \quad L_{5}, \quad\left(L_{5}-52.5^{\circ}\right), \quad\left(L_{5}-105^{\circ}\right), \quad\left(L_{5}-\right.$ $\left.157.5^{\circ}\right),\left(L_{5}-210^{\circ}\right)$, and $\left(L_{5}-262.5^{\circ}\right) \pm 8^{\circ}$.

\section{B. Collision Avoidance}

The separations of FORMOSAT-3 spacecraft from the final stage of the launch vehicle relied on the separation mechanism built into the structure of each spacecraft. All the six satellites were injected, heading along the velocity direction. The separation of each spacecraft from the spacecraft stack and the final stage of the launch vehicle obey the conservation laws of momentum and energy. As a result of calculation, the velocity after separation should be $V_{\mathrm{FM} 1}>V_{\mathrm{FM} 2}>V_{\mathrm{FM} 3}>V_{\mathrm{FM} 4}>$ $V_{\mathrm{FM} 5}>V_{\mathrm{FM} 6}$ [27], [28].

We conclude that the spacecraft will not collide with each other because the velocity of spacecraft $N$ is always faster than the velocity of spacecraft $N+1$. When taking into account the variance and the accuracy of measurement, there may be approximately $12.5 \%$ variance in the energy of the spring in the case of FORMOSAT-3. To avoid collisions, the compression of the sets of springs for each spacecraft is different: $x_{\mathrm{FM} 1}>$ $x_{\mathrm{FM} 2}>x_{\mathrm{FM} 3}>x_{\mathrm{FM} 4}>x_{\mathrm{FM} 5}>x_{\mathrm{FM} 6}$. The resulting separation simulation results are shown in Fig. 8. The separation intervals are set at $60 \mathrm{~s}$. The higher dashed line represents $+12.5 \%$ of specified spring energy, and the lower dashed line represents $-12.5 \%$. Distance $=0$ represents an imaginary object which is the nonseparated final stage and spacecraft suite. The different slopes correspond to different velocities. If the lines do not intersect, no collision is expected to happen.

\section{Separation Sequence}

Ten days before launch, NSPO was informed that there is unexpected residual thrust in the final stage of the launch vehicle as the first separation is triggered. Additional simulation analyses were performed; the results indicated that the relative

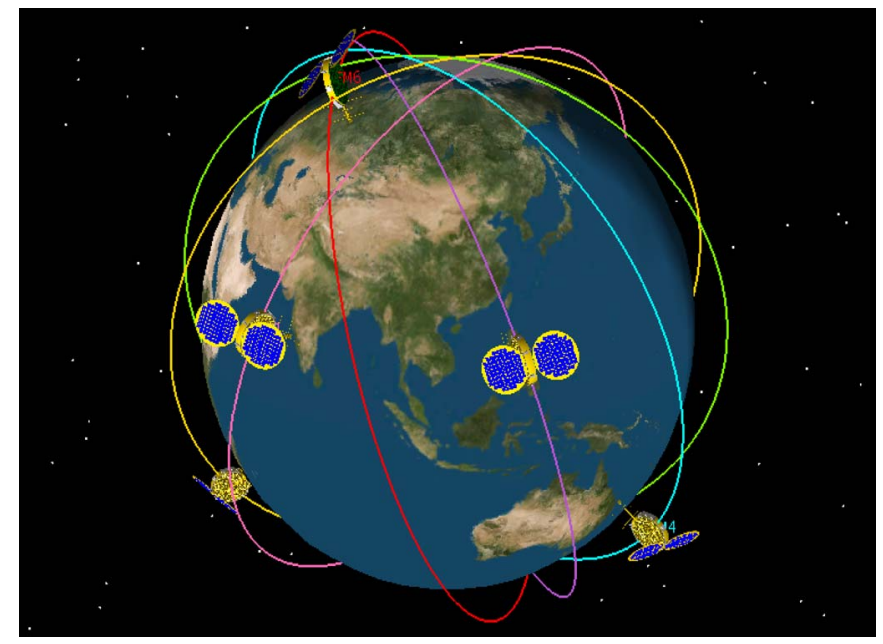

Fig. 9. FORMOSAT-3/COSMIC final constellation.

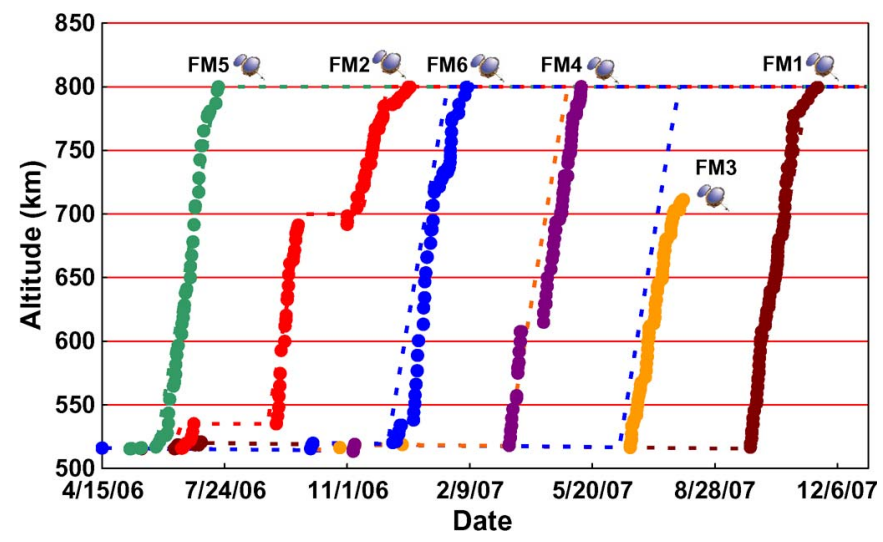

Fig. 10. FORMOSAT-3/COSMIC as-is burn history and deployment timeline.

positions with respect to the six satellites and final stage are adequate to avoid collision. However, the effect of residual thrust did result in changes to the spacecraft sequence. The expected spacecraft sequence should be FM6 $->$ FM5 $->$ FM4 $->$ FM3 $->$ FM2 $->$ FM1 based on the designed installation of a separation spring without the fourth stage residual thrust. The satellite cluster sequence with the anticipated fourth stage residual thrust after launch became FM6 $->$ FM1 $->$ FM5 $->$ FM4 $->$ FM3 $->$ FM2. FM1 has lagged behind as expected in the cluster sequence since it has the least effect due to the fourth stage residual thrust. This sequence change has no practical impact on flight or mission operations [27], [28].

\section{Spacecraft Constellation Deployment}

During the L\&EO phase, the satellites were separated one by one into the same injection orbit with the same RAAN and RAAN drift rate. The strategy to differentiate the RAANs among the six orbits is to maneuver the six satellites into the mission orbit altitude of $800 \mathrm{~km}$ at different "maneuvering windows" (typically 45 days) in the year in order to get into the designated separate orbital planes through nodal precession. All satellites reach their final orbits with each designed RAAN and AOL at this phase [37], [41]. The FORMOSAT-3/COSMIC mission is the first "proof-of-concept" mission to use OSC 
TABLE II

Constellation Deployment Status With Five Satellites (FM5, FM2, FM6, FM4, And FM1) at Final Orbits as of Dec. 2,2007

\begin{tabular}{|c|c|c|c|c|c|}
\hline SC No. & $\begin{array}{c}\text { SMA } \\
(\mathrm{km})\end{array}$ & Eccentricity & $\begin{array}{c}\text { Inclination } \\
(\mathrm{deg})\end{array}$ & $\begin{array}{c}\text { RAAN }(\Omega \mathrm{i} / 5) \\
(\mathrm{deg})\end{array}$ & $\begin{array}{c}\text { AOL }(\mathrm{Li} / 5) \\
(\mathrm{deg})\end{array}$ \\
\hline FM5 & 799.475 & 0.0046 & 71.973 & 0 & 0 \\
\hline FM2 & 799.449 & 0.0041 & 72.037 & 29.9 & 50.7 \\
\hline FM6 & 799.444 & 0.0051 & 71.982 & 62.0 & 104.4 \\
\hline FM4 & 799.471 & 0.0072 & 72.009 & 90.0 & 158.2 \\
\hline FM3* & 711.047 & 0.0054 & 72.012 & 129.9 & Time Variant \\
\hline FM1 & 799.475 & 0.0046 & 71.973 & 145.9 & 262.53 \\
\hline
\end{tabular}

*Note: On 3 Aug. 2007 the FM3 encountered solar array drive mechanism malfunction when reached 711 km orbit.

constellation deployment patent [43]. The detailed constellation deployment principles have been described in Section III-C, and the as-burn constellation results are described in Section V.

\section{E. Final Constellation and Extended Mission}

The final constellation of FORMOSAT-3 has six orbit planes, as shown in Fig. 9. Each orbit is at an altitude of $800 \mathrm{~km}$ with an inclination angle of $72^{\circ}$. The separation angle among orbit planes is $30^{\circ}$, and the AOL separation between satellites in adjacent orbit planes is of $52.5^{\circ}$. The final constellation allows the six satellites to collect 2500 atmospheric sounding data on an average per day worldwide.

\section{Constellation Deployment Results}

\section{A. As-Burn Constellation Results}

The current constellation configuration as of December 2007 is five satellites (FM5, FM2, FM6, FM4, and FM1) successfully reaching the 800-km mission orbits. On August 3, 2007, FM3 encountered the SAD mechanism malfunction when reaching the 711-km orbit. This anomaly blocks the FM3 thrust-burn activity to be deployed at the $800-\mathrm{km}$ mission orbit. The reasons for this anomaly are still under investigation. The current constellation status is shown in Fig. 10. The dashed line is the newly planned schedule, and the dots recorded the execution results of the thrusting. The relative orbital separation angle, AOL, and altitudes of these four satellites are shown in Table II.

\section{B. Spacecraft Thrust-Burn Performance Statistics}

Fig. 11 and Table III show the spacecraft thrust-burn performance statistic results in strip chart and table formats, respectively. Starting from FM4 orbit transfer, the NSPO operation team uses the autopilot scheme to increase the burn success rate and reduce the burn working days. The data show that the FM5 burn working days number 39. However, it takes 75 calendar days to complete the burn activities. The operation team scheduled seven burns per day for FM4 and FM1 compared to three burns per day for FM5, as deployed earlier. The better spacecraft burn performance indicates that more successful rate has been achieved. The operation team has decreased the planned burn duration from 456 min for FM5 to $382.8 \mathrm{~min}$ for FM1 and also decreased the executed burn duration from 326.1 min for FM5 to 329.8 min for FM1. These results show

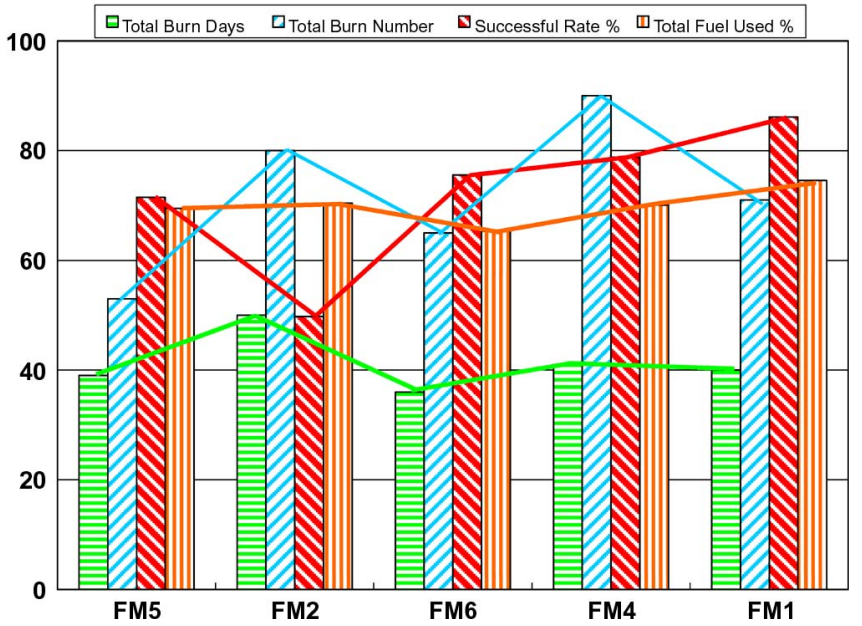

Fig. 11. Spacecraft thrust-burn performance statistics.

that the thrust-burn success rate (= executed/planned burn) has been increased by the operation team from $71.5 \%$ for FM5 to $86.2 \%$ for FM1. Total burn number has increased from 53 times in FM5 to 71 times in FM1. In Table III, it can be seen that the average orbit-transfer height per burn has decreased from $5.4 \mathrm{~km} / \mathrm{burn}$ for FM5 to $3.4 \mathrm{~km} /$ burn for FM1. In addition, the average burn duration per burn has decreased from $369.4 \mathrm{~s} / \mathrm{burn}$ for FM5 to 238.4 s/burn for FM1.

\section{Spacecraft Mass Property and MOI Results}

We found that the propellant mass remains in the propellant tank are about $2.0 \mathrm{~kg}$ after the orbit-transfer operations are completed for each satellite. It is also expected that the spacecraft mass property [weight and center of gravity (CG)] and the moment of inertia (MOI) are changed accordingly when the propellant mass is changed. It was observed that the spacecraft CG has a change of $-0.7-\mathrm{cm}$ shift in $Z$-axis before and after orbit-transfer activities and has a CG shift in $-Y$ and $-X$ axes too. These changes will have a significant impact on the geodesy and earth gravity research. Table IV shows the spacecraft mass property and MOI results of the six satellites. The spacecraft remaining propellant mass was estimated and provided by propulsion subsystem. The error of the mass was estimated in the range of $\pm 0.1 \mathrm{~kg}$. Based on computation results, a very minor impact on MOI and CG results was observed due to this error range. 
TABLE III

Spacecraft Thrust-Burn Performance Statistic

\begin{tabular}{|c|c|c|c|c|c|c|c|c|c|}
\hline Items & $\begin{array}{c}\text { Total Burn } \\
\text { Days } \\
\text { SC No. }\end{array}$ & $\begin{array}{c}\text { Total Burn } \\
\text { Number } \\
(\mathrm{no})\end{array}$ & $\begin{array}{c}\text { Planned } \\
\text { Burn } \\
(\text { Minutes })\end{array}$ & $\begin{array}{c}\text { Executed } \\
\text { Burn } \\
(\text { Minutes })\end{array}$ & $\begin{array}{c}\text { Successful } \\
\text { Rate } \\
(\%)\end{array}$ & $\begin{array}{c}\text { Total Fuel } \\
\text { Used } \\
(\mathrm{kg})\end{array}$ & $\begin{array}{c}\text { Total Fuel } \\
\text { Mass } \\
(\mathrm{kg})\end{array}$ & $\begin{array}{c}\text { Average } \\
\text { SMA/burn } \\
(\mathrm{km} / \mathrm{burn})\end{array}$ & $\begin{array}{c}\text { Average } \\
\text { Duration/burn } \\
(\mathrm{sec} / \mathrm{burn})\end{array}$ \\
\hline FM5 & 39 & 53 & 456 & 326.1 & 71.5 & 4.634 & 6.671 & 5.4 & 369.4 \\
\hline FM2 & 50 & 80 & 646.5 & 321.7 & 49.8 & 4.686 & 6.651 & 3.6 & 241 \\
\hline FM6 & 36 & 65 & 390 & 294.7 & 75.6 & 4.332 & 6.635 & 4.4 & 279.9 \\
\hline FM4 & 41 & 90 & 390.5 & 307.8 & 78.8 & 4.644 & 6.627 & 3.2 & 205.4 \\
\hline FM3 & 39 & 74 & 265.7 & 190.3 & 71.6 & 3.345 & 6.665 & 2.7 & 154.3 \\
\hline FM1 & 40 & 71 & 382.8 & 329.8 & 86.2 & 4.993 & 6.697 & 3.4 & 238.4 \\
\hline
\end{tabular}

TABLE IV

Spacecraft Mass Property and MOI for Six Satellites as of DeC. 2, 2007

\begin{tabular}{|c|c|c|c|c|c|c|c|}
\hline Items & $\begin{array}{c}\text { Total Mass } \\
\text { (Full } \\
\text { Tank) }\end{array}$ & $\begin{array}{l}\text { Remaining } \\
\text { SC Total } \\
\text { Mass }\end{array}$ & $\begin{array}{l}\text { Remaining } \\
\text { Propellant } \\
+/-0.1 \mathrm{~kg}\end{array}$ & $\begin{array}{l}\text { Center of } \\
\text { Gravity } \\
\text { (CG) }\end{array}$ & \multicolumn{3}{|c|}{$\begin{array}{l}\text { Moment of Inertia } \\
(\mathrm{MOI}) \\
\text { Assume SAD }=0 \mathrm{deg}\end{array}$} \\
\hline SC No. & $(\mathrm{kg})$ & $(\mathrm{kg})$ & $(\mathrm{kg})$ & $(\mathrm{m})$ & \multicolumn{3}{|c|}{$\mathrm{kg} \mathrm{m}^{2}$} \\
\hline FM1 & 61.097 & 56.104 & $\begin{array}{c}1.704 \\
(94 \mathrm{psi} / \\
\left.13.2^{\circ} \mathrm{C}\right)\end{array}$ & $\begin{array}{l}x=0.0035084 \\
y=-0.0043757 \\
z=-0.0334029\end{array}$ & $\begin{array}{l}\mathrm{Ixx}=7.1677273 \\
\mathrm{Iyx}=0.0288131 \\
\mathrm{Izx}=-0.0071984\end{array}$ & $\begin{array}{l}\text { Ixy }=0.0288131 \\
\text { Iyy }=10.0887230 \\
\text { Izy }=-0.4359628\end{array}$ & $\begin{array}{l}\mathrm{Ixz}=-0.0071984 \\
\mathrm{Iyz}=-0.4359628 \\
\mathrm{Izz}=5.2806052\end{array}$ \\
\hline FM2 & 61.295 & 56.609 & $\begin{array}{c}1.965 \\
(100 \mathrm{psi} / \\
\left.12.68^{\circ} \mathrm{C}\right)\end{array}$ & $\begin{array}{l}x=-0.0034182 \\
y=-0.0041841 \\
z=-0.0364667\end{array}$ & $\begin{array}{l}\mathrm{Ixx}=6.9711402 \\
\mathrm{Iyx}=0.0292363 \\
\mathrm{Izx}=-0.0096030\end{array}$ & $\begin{array}{l}\mathrm{Ixy}=0.0292363 \\
\mathrm{Iyy}=9.8405863 \\
\mathrm{Izy}=-0.4376625\end{array}$ & $\begin{array}{l}\mathrm{Ixz}=-0.0096030 \\
\mathrm{Iyz}=-0.4376625 \\
\mathrm{Izz}=5.2101918\end{array}$ \\
\hline FM3 & 61.295 & 57.950 & $\begin{array}{c}3.320 \\
(129 \mathrm{psi} / \\
\left.27.86^{\circ} \mathrm{C}\right)\end{array}$ & $\begin{array}{l}x=-0.0015454 \\
y=-0.0070990 \\
z=-0.0367495\end{array}$ & $\begin{array}{l}\mathrm{Ixx}=7.0538797 \\
\mathrm{Iyx}=0.3262446 \\
\mathrm{Izx}=0.1441285\end{array}$ & $\begin{array}{l}\text { Ixy }=0.3262446 \\
\text { Iyy }=9.8458681 \\
\text { Izy }=-0.2834290\end{array}$ & $\begin{array}{l}\mathrm{Ixz}=0.1441285 \\
\mathrm{Iyz}=-0.2834290 \\
\mathrm{Izz}=5.1711034\end{array}$ \\
\hline FM4 & 61.020 & 56.376 & $\begin{array}{c}1.983 \\
(105 \mathrm{psi} / \\
\left.29.10^{\circ} \mathrm{C}\right)\end{array}$ & $\begin{array}{l}x=-0.0037843 \\
y=-0.0073189 \\
z=-0.0371947\end{array}$ & $\begin{array}{l}\mathrm{Ixx}=6.8193710 \\
\mathrm{Iyx}=0.0317362 \\
\mathrm{Izx}=0.0744942\end{array}$ & $\begin{array}{l}\text { Ixy }=0.0317362 \\
\text { Iyy }=9.7484668 \\
\text { Izy }=-0.4389625\end{array}$ & $\begin{array}{l}\mathrm{Ixz}=0.0744942 \\
\mathrm{Iyz}=-0.4389625 \\
\mathrm{Izz}=4.8734748\end{array}$ \\
\hline FM5 & 61.167 & 56.533 & $\begin{array}{c}2.037 \\
(98 \mathrm{psi} / \\
\left.13.68^{\circ} \mathrm{C}\right)\end{array}$ & $\begin{array}{l}x=-0.0036067 \\
y=-0.0045262 \\
z=-0.037113\end{array}$ & $\begin{array}{l}\mathrm{Ixx}=6.9437632 \\
\mathrm{Iyx}=0.0275360 \\
\mathrm{Izx}=-0.0087138\end{array}$ & $\begin{array}{l}\mathrm{Ixy}=0.0275360 \\
\mathrm{Iyy}=9.8007081 \\
\mathrm{Izy}=-0.4379625\end{array}$ & $\begin{array}{l}\mathrm{Ixz}=-0.0087138 \\
\mathrm{Iyz}=-0.4379625 \\
\mathrm{Izz}=5.2086237\end{array}$ \\
\hline FM6 & 61.315 & 56.983 & $\begin{array}{c}2.303 \\
(106 \mathrm{psi} / \\
\left.18.40^{\circ} \mathrm{C}\right)\end{array}$ & $\begin{array}{l}x=-0.0032281 \\
y=-0.0044101 \\
z=-0.0360353\end{array}$ & $\begin{array}{l}\mathrm{Ixx}=6.9827399 \\
\mathrm{Iyx}=0.0289346 \\
\mathrm{Izx}=-0.0115537\end{array}$ & $\begin{array}{l}\text { Ixy }=0.0289346 \\
\text { Iyy }=9.8596525 \\
\text { Izy }=-0.4397625\end{array}$ & $\begin{array}{l}\mathrm{Ixz}=-0.0115537 \\
\mathrm{Iyz}=-0.4397625 \\
\mathrm{Izz}=5.2408835\end{array}$ \\
\hline
\end{tabular}

In the FORMOSAT- 3 satellite case, the TBB boom and the solar panels are two portions that are deployed after satellite separation from the launch vehicle. The propellant fuel is also changed after orbit transfer. For the MOI computation, we assume that the $\mathrm{SAD}$ is at $0^{\circ}$ position. The CG is valid for any SAD position and therefore applies to the ACS nadir and nadir-yaw modes. The MOI and CG for six spacecraft were recomputed based on the aforementioned propellant mass.

\section{ORbit-RAising Challenges AND LESSONS LEARNED}

\section{A. Thrust-Burn Failures and Challenges}

NSPO experienced numerous thrust-burn failures during the spacecraft constellation deployment of FM5 [44]. By analyzing the spacecraft back-orbit data and using the animation result of the dynamic engineering development model simulator with real telemetry data, we observed and summarized that the thrust-burn failure was attributed to the incorrect thrust-burn modeling and the incorrect spacecraft mass property and MOI data. The thrust gain factor in the spacecraft model is designed to be adjustable by the spacecraft ground command. By adjust- ing the thrust PID gain "factor" for roll and yaw, the reduction factor for the thrust torque $(R \times F)$, and the ACS common spacecraft database parameters, the thrust-burn activity was continued and performed successfully. The major impact of the thrust-burn failure is that the operation team could not perform the full burn (turn ON thruster $0.8 \mathrm{~s}$ in 2 -s control cycle) by routine process as planned. This caused a significant schedule slip in the first orbit-transfer activities for FM5 [28], [41], [42].

\section{B. Spacecraft Attitude Excursion Challenges}

Another lesson learned from the follow-on FM2 and FM6 thrust-burn activities comes from the spacecraft attitude excursion challenge. From the thrust-burn history statistics, it was observed that the orbit-transfer activities were performed very successfully with a $100 \%$ success rate when the thrustburn activity was planned during the spacecraft eclipse time period. However, it was also observed that the orbit-transfer activities were performed unsuccessfully with around a 50\% success rate when thrust-burn activity was planned during the spacecraft daytime period. The source of this attitude excursion problem for daytime thrust-burn activity is the fact that the sensor-processing algorithm used for the spacecraft ARS to 
perform attitude control will sometimes generate incorrect sun vector solutions, depending upon the numbers of cosine sun sensors. As soon as the algorithm generates an unreliable sun vector output solution to the ARS, the ARS and the ACS will immediately generate a large attitude transient incident when responding to the error [32], [39], [40].

\section{Automation of Ground Operation Procedure}

It usually takes two station contacts for a thrust-burn: one contact to upload the burn commands and the other to check out the burn results. This constrains the thrust operation to two burns per day. To increase the number of burns per day, the operation team developed a Satellite Test and Operations Language (STOL) procedure to generate the burn command sequence. After checking out the burn results during a station contact, the STOL procedure could extract the postburn data of tank pressure, thrust power, and control integral terms from the telemetry. The tank pressure was used to calculate the thrust force level. The thrust power and integral terms were used as the initial conditions of the next thrusting. With these data from the telemetry, the STOL procedure could generate and upload the time-tag commands for the next burn during the same station contact. The STOL procedure increased the operation efficiency to one burn per orbit. Three burns or more (seven burns were achieved at once) are planned per day to increase the operation flexibility and efficiency [32], [39].

\section{RTS Ground Support Limitation}

The operation team needs to observe the results of the thrust burn from the real-time telemetry and then estimate the corresponding two line elements as the inputs to ground antenna pointing. During 00:00:00-06:00:00 UTC, Kiruna remote tracking station (RTS) is not staffed, so that they cannot support the update of the North American Aerospace Defense Command two-line elements. This constraint impacted the thrusting operations to be conducted after 06:00:00 UTC if the postburn contact station is Kiruna [32], [40].

\section{CONCLUSION}

We have presented in this paper a new fundamental operation concept for the FORMOSAT-3/COSMIC spacecraft constellation deployment, orbit-raising results, operations challenges, and lessons learned. With five satellites (FM5, FM2, FM6, FM4, and FM1) successfully reaching the $800-\mathrm{km}$ mission orbits as of November 2007, the FORMOSAT-3/COSMIC mission has verified the "proof of concept" of a novel way of performing constellation deployment by taking the advantage of nodal precession. This novel approach has dramatically reduced the spacecraft propellant mass and the complexity of the spacecraft RCS and ACS subsystem design. The success of the constellation deployment of the FORMOSAT-3/COSMIC mission has also provided a powerful demonstration of RO scheme in particular and for the remote-sensing applications of microsatellite constellations in general. All these technical principles have paved the way for the design of future GNSS RO remote-sensing systems.

\section{ACKNOWLEDGMENT}

The authors have gained a great deal of unique practical experience and lessons learned from the mission definition, system design, system integration and test, launch integration and operations, and constellation mission operations through the cooperation with international agencies. They would like to thank the contributions of the FORMOSAT-3/COSMIC program, mission operation, flight operation, ground operation, constellation deployment, and anomaly resolution teams; the Taiwan science teams; and the cooperation partners with the National Science Council, Central Weather Bureau, National Science Foundation, UCAR, National Center for Atmospheric Research, JPL/NASA, NRL, U.S. Air Force, National Oceanic and Atmospheric Administration, and OSC.

\section{REFERENCES}

[1] G. Fjeldbo and V. R. Eshleman, "The bistatic radar-occultation method for the study of planetary atmospheres," J. Geophys. Res., vol. 70, pp. 3217-3225, 1965.

[2] A. J. Kliore, D. L. Cain, G. S. Levy, V. R. Eschleman, G. Fjeldbo, and F. D. Drake, "Occultation experiment: Results of the first direct measurement of Mars' atmosphere and ionosphere," Science, vol. 149, no. 3689, pp. 1243-1248, Sep. 1965.

[3] B. Lusignan, G. Modrell, A. Morrison, J. Pomalaza, and S. G. Ungar, "Sensing the Earth's atmosphere with occultation satellites," Proc. IEEE, vol. 57, no. 4, pp. 458-467, Apr. 1969.

[4] W. G. Melbourne, E. S. Davis, C. B. Duncan, G. A. Hajj, K. R. Hardy, E. R. Kursinski, T. K. Meehan, L. E. Young, and T. P. Yunck, The Application of Spaceborne GPS to Atmospheric Limb Sounding and Global Change Monitoring. Pasadena, CA: Jet Propulsion Lab., Apr. 1994. JPL Publication 94-18.

[5] T. P. Yunck, C. H. Liu, and R. Ware, "A history of GPS sounding," Terr., Atmos. Ocean. Sci. (TAO), vol. 11, pp. 1-20, Mar. 2000.

[6] A. S. Liu, "On the determination and investigation of the terrestrial ionospheric refractive indices using GEOS-3/ATS-6 satellite-to-satellite tracking data," Jet Propulsion Lab., Pasadena, CA, NASA-CR-156848, Nov. 1978.

[7] O. Yakovlev, I. Matyugov, and I. A. Vilkov, "Radio-wave phase and frequency fluctuations as observed in radio occultation experiments on the satellite-to-satellite link," J. Commun. Technol. Electron., vol. 41, no. 11, pp. 993-998, 1996.

[8] T. P. Yunck, W. G. Melbourne, and C. L. Thornton, "GPS-based satellite tracking system for precise positioning," IEEE Trans. Geosci. Remote Sens., vol. GRS-23, no. 4, pp. 450-457, Jul. 1985.

[9] T. P. Yunck, G. F. Lindal, and C. H. Liu, "The role of GPS in precise Earth observation," in Proc. IEEE PLANS Rec.-'Navigation Into the 21st Century', Nov. 29-Dec. 2, 1988, pp. 251-258.

[10] T. P. Tunck, S. C. Wu, J. T. Wu, and C. L. Thornton, "Precise tracking of remote sensing satellites with the Global Positioning System," IEEE Trans. Geosci. Remote Sens., vol. 28, no. 1, pp. 108-116, Jan. 1990.

[11] S. C. Wu and W. G. Melbourne, "An optimal GPS data processing technique for precise positioning," IEEE Trans. Geosci. Remote Sens., vol. 31, no. 1, pp. 146-152, Jan. 1993.

[12] R. Ware, C. Rocken, F. Solheim, M. Exner, W. Schreiner, R. Anthes, D. Feng, B. Herman, M. Gorbunov, S. Sokolovskiy, K. Hardy, Y. Kuo, X. Zou, K. Trenberth, T. Meehan, W. Melbourne, and S. Businger, "GPS sounding of the atmosphere from low Earth orbit: Preliminary results," Bull. Amer. Meteorol. Soc. (BAMS), vol. 77, no. 1, pp. 19-40, Jan. 1996.

[13] E. R. Kursinski, G. A. Hajj, W. I. Bertiger, S. S. Leroy, T. K. Meehan, L. J. Romans, J. T. Schofield, D. J. McCleese, W. G. Melbourne, C. L. Thornton, T. P. Yunck, J. R. Eyre, and R. N. Nagatani, "Initial results of radio occultation observations of Earth's atmosphere using the Global Positioning System," Science, vol. 271, no. 5252, pp. 1107-1110, Feb. 1996.

[14] A. Rius, G. Ruffini, and A. Romeo, "Analysis of ionospheric electrondensity distribution from GPS/MET occultations," IEEE Trans. Geosci. Remote Sens., vol. 36, no. 2, pp. 383-394, Mar. 1998.

[15] R. A. Anthes, C. Rocken, and Y. H. Kuo, "Application of COSMIC to meteorology and climate," Terr., Atmos. Ocean. Sci. (TAO), vol. 11, pp. 115-156, Mar. 2000. 
[16] E. R. Kursinski, G. A. Hajj, S. S. Leroy, and B. Herman, "The GPS occultation technique," Terr., Atmos. Ocean. Sci. (TAO), vol. 11, pp. 53-114, Mar. 2000.

[17] G. A. Hajj, L. C. Lee, X. Pi, L. J. Romans, W. S. Schreiner, P. R. Straus, and C. Wang, "COSMIC GPS ionospheric sensing and space weather," Terr., Atmos. Ocean. Sci. (TAO), vol. 11, no. 1, pp. 235-272, Mar. 2000.

[18] Y.-H. Kuo, T.-K. Wee, S. Sokolovskiy, C. Rocken, W. Schreiner, D. Hunt, and R. A. Anthes, "Inversion and error estimation of GPS radio occultation data," J. Meteorol. Soc. Jpn., vol. 82, no. 1B, pp. 507-531, 2004.

[19] Y.-A. Liou, A. G. Pavelyev, C.-Y. Huang, K. Igarashi, and K. Hocke, "Simultaneous observation of the vertical gradients of refractivity in the atmosphere and electron density in the lower ionosphere by radio occultation amplitude method," Geophys. Res. Lett., vol. 29, no. 19, pp. 43-1-43-4, 2002. DOI: 10.1029/2002GL015155.

[20] Y.-A. Liou, A. G. Pavelyev, C.-Y. Huang, K. Igarashi, K. Hocke, and S.-K. Yan, "An analytic method for observing the gravity waves using radio occultation data," Geophys. Res. Lett., vol. 30, no. 20, p. 2021, 2003. DOI: 10.1029/2003GL017818.

[21] Y.-A. Liou, A. G. Pavelyev, J. Wickert, T. Schmidt, and A. A. Pavelyev, "Analysis of atmospheric and ionospheric structures using the GPS/MET and CHAMP radio occultation data base: A methodological review," GPS Solut., vol. 9, no. 2, pp. 122-143, 2005. DOI: 10.1007/s10291-0050141-y.

[22] Y.-A. Liou, A. G. Pavelyev, and J. Wickert, "Observation of the gravity waves from GPS/MET radio occultation data," J. Atmos. Sol.-Terr. Phys., vol. 67, no. 3, pp. 219-228, Feb. 2005.

[23] Y.-A. Liou, A. G. Pavelyev, J. Wickert, S. F. Liu, A. A. Pavelyev, T. Schmidt, and K. Igarashi, "Application of GPS radio occultation method for observation of the internal waves in the atmosphere," J. Geophys. Res., vol. 111, no. D6, p. D06 104, Mar. 2006. DOI: 10.1029/2005JD005823.

[24] Y.-A. Liou and A. G. Pavelyev, "Simultaneous observations of radio wave phase and intensity variations for locating the plasma layers in the ionosphere," Geophys. Res. Lett., vol. 33, no. 23, p. L23 102, Dec. 2006. DOI:10.1029/2006GL027112

[25] C.-J. Fong, B. H. Wu, N. Yen, and P. Chen, "Application of FORMOSAT-3/COSMIC mission to global Earth monitoring," presented at the AIAA SPACE Conf. and Exposition, Long Beach, CA, Aug. 30-Sep. 1, 2005, Paper AIAA-2005-6774.

[26] B. H. Wu, C.-J. Fong, C. Y. Huang, Y. A. Liou, N. Yen, and P. Chen, "FORMOSAT-3/COSMIC mission to global Earth weather monitoring, operation, and TACC/CDAAC post-processing," presented at the 86th AMS Annu. Meeting-14th Conf. Satellite Meteorology and Oceanography, Atlanta, GA, Jan. 29-Feb. 2, 2006

[27] C. H. Chu, A.-M. Wu, C.-Y. Huang, T.-Y. Liu, S.-K. Yang, and L. Yen, "FORMOSAT-3 mission operations review and prospect," presented at the FORMOSAT-3/COSMIC Workshop-Early Results and IOP Campaign, Taipei, Taiwan, Nov. 28-Dec. 1, 2006.

[28] C.-J. Fong, N. L. Yen, C.-H. Chu, S.-K. Yang, W.-T. Shiau, C.-Y. Huang, S. Chi, S.-S. Chen, Y. A. Liou, and Y. H. Kuo, "FORMOSAT-3/COSMIC spacecraft constellation system, mission results, and prospect for followon mission," Terr., Atmos. and Ocean. Sci. (TAO), vol. 20, no. 1, Jan. 2009.

[29] R. A. Anthes, P. A. Bernhardt, Y. Chen, L. Cucurull, K. F. Dymond, D. Ector, S. B. Healy, S.-P. Ho, D. C. Hunt, Y.-H. Kuo, H. Liu, K. Manning, C. McCormick, T. K. Mehan, W. J. Randel, C. Rocken, W. S. Schreiner, S. V. Sokolovskiy, S. Syndergaard, D. C. Thompson, K. E. Trenberth, T. K. Wee, N. L. Yen, and Z. Zeng, "The COSMIC/ FORMOSAT-3 mission: Early results," in Bull. Amer Meteorol. Soc. (BAMS), vol. 89, Mar. 2008, pp. 313-333. DOI: 10.1175/BAMS-893-xxx.

[30] C.-Z. F. Cheng, Y.-H. Kuo, R. A. Anthes, and L. Wu, "Satellite constellation monitors global and space weather," EOS Trans. Amer. Geophys. Union, vol. 87, no. 17, pp. 166-167, Apr. 2006.

[31] Y.-A. Liou, A. G. Pavelyev, S.-F. Liu, A. A. Pavelyev, N. Yen, C.-Y. Huang, and C.-J. Fong, "FORMOSAT-3/COSMIC GPS radio occultation mission: Preliminary results," IEEE Trans. Geosci. Remote Sens., vol. 45, no. 11, pp. 3813-3826, Nov. 2007. DOI: 10.1109/TGRS. 2007.903365

[32] C.-J. Fong, C. Y. Huang, V. Chu, A. Hsiao, E. Yang, N. Yen, S. S. Chen, D. Hawes, Y.-H. Kuo, Y.-A. Liou, and S. Chi, "Mission results from FORMOSAT-3/COSMIC constellation system," presented at the AIAA SPACE Conf. and Exposition, Long Beach, CA, Sep. 18-20, 2007, Paper AIAA-2007-6086.

[33] C.-J. Fong, C. Y. Huang, V. Chu, N. Yen, Y.-H. Kuo, Y.-A. Liou, and S. Chi, "Mission results from FORMOSAT-3/COSMIC constellation system,” AIAA J. Spacecr. Rockets, 2008. DOI: 10.2514/1.34427.
[34] C.-J. Fong, N. Yen, S. K. Yang, S. S. Chen, and S. Chi, "GPS radio occultation and mission results from FORMOSAT-3/COSMIC spacecraft constellation," in Proc. 3rd Int. Conf. Recent Advances Spacecr. Technol., Istanbul, Turkey, Jun. 14-16, 2007. DOI: 10.1109/RAST.2007.4284093.

[35] N. Yen, C.-J. Fong, V. Chu, A. Hsiao, T. Tsai, and C. Y. Huang, "FORMOSAT-3/COSMIC mission to global Earth weather monitoring: Early orbit, orbit transfer and mission operation overview," presented at the FORMOSAT-3/COSMIC Data Users Workshop, Boulder, CO, Oct. 16-18, 2006.

[36] A. Shiau, C.-J. Fong, V. Chu, T. Lin, T. C. Kuo, and N. Yen, "FORMOSAT-3/COSMIC orbit raising and constellation deployment," presented at the FORMOSAT-3/COSMIC Workshop-Early Results and IOP Campaign, Taipei, Taiwan, Nov. 28-Dec. 1, 2006

[37] A. Shiau and R. Kuo, "FORMOSAT-3 constellation deployment plan," Nat. Space Org., Hsin-Chu, Taiwan, Tech. Rep. NSPO-PLAN0009 0000, Jun. 2006.

[38] E. Yang, V. Chu, V. Chang, A. Hsiao, V. Huang, T. Tsai, C.-J. Fong, and R. Lo, "Operations solutions to spacecraft anomalies and technical difficulties," presented at the FORMOSAT-3/COSMIC Workshop-Early Results and IOP Campaign, Taipei, Taiwan, Nov. 28-Dec. 1, 2006.

[39] C.-J. Fong, T. Tsai, E. Yang, R. Lo, J. Yeh, C.-R. Chen, M.-S. Chang, T. Lin, M. Yeh, T.-C. Kuo, C.-Y. Huang, C.-H. Lin, C.-C. Hsiao, V. Chu, and N. Yen, "System evaluation and on-orbit performance of the FORMOSAT-3/COSMIC constellation mission," presented at the FORMOSAT-3/COSMIC Workshop-Early Results and IOP Campaign, Taipei, Taiwan, Nov. 28-Dec. 1, 2006.

[40] C.-J. Fong, S.-K. Yang, C.-H. Chu, C.-Y. Huang, J.-J. Yeh, C.-T. Lin, T.-C. Kuo, T.-Y. Liu, N. Yen, S. S. Chen, Y.-H. Kuo, Y.-A. Liou, and S. Chi, "FORMOSAT-3/COSMIC constellation spacecraft system performance: After one year in orbit," IEEE Trans. Geosci. Remote Sens., vol. 46 , no. 11 , Nov. 2008

[41] C.-J. Fong, N. Yen, V. Chu, S. S. Chen, and S. Chi, "Operations challenges from the FORMOSAT-3/COSMIC constellation for global Earth weather monitoring," in Proc. IEEE Aerosp. Conf., Big Sky, MT, Mar. 3-10, 2007, pp. 1-14. DOI: 10.1109/AERO.2007.352986.

[42] C.-H. V. Chu, S.-K. Yang, C.-J. Fong, N. Yen, T.-Y. Liu, W.-J. Chen, D. Hawes, Y.-A. Liou, and Y.-H. Kuo, "The most accurate and stable space-borne thermometers-FORMOSAT-3/COSMIC constellation," in Proc. 21st Аnпи. AIAA/USU Conf. Small Satellites, Logan, UT, Aug. 13-16, 2007, vol. SSC07-VII-1.

[43] J. A. King and N. J. Beidleman, "Method and apparatus for deploying a satellite network," U.S. Patent 5199 672, May 25, 1990.

[44] J. R. Wertz, "Summary of orbit properties and terminologySpacecraft orbits," in Spacecraft Attitude Determination and Control, J. R. Wertz, Ed. Dordrecht, The Netherlands: Kluwer, 1978, ch. 3, sec. 3, p. 68. Eq. (3-41d).

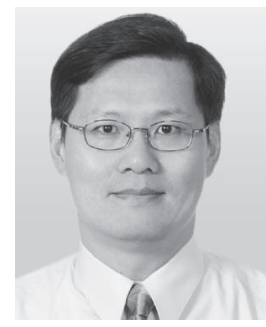

Chen-Joe Fong (S'04-M'08) received the B.S.E.E. and M.S.E.E. degrees in electrophysics and electrooptical engineering from the National Chiao Tung University, Hsinchu, Taiwan, in 1983 and 1985, respectively, where he is currently working toward the Ph.D. degree in the Department of Photonics and Institute of Electro-Optical Engineering.

$\mathrm{He}$ is also the FORMOSAT-3 Program Systems Engineering Manager with the Systems Engineering Division, National Space Organization (NSPO), Hsinchu. During the FORMOSAT-3/COSMIC mission operation phase, he is a Spacecraft Lead and responsible for the anomaly resolution team. He has been with NSPO since 1993 and later acted as the Satellite Integration and Test (I\&T) Project Manager of ROCSAT-1 program and the I\&T Division Director. From 1987 to 1993, he was with the Center for Measurement Standards as a Microwave Lab Head and Systems Engineer in the Center for Aviation and Space Technology, Industrial Technology Research Institute, for the ROCSAT-1 program. His current research interests include incoherent time domain pump fiber Raman amplifier, optical soliton, GPS radio occultation, systems engineering, and mission simulation.

Mr. Fong is a member of American Institute of Aeronautics and Astronautics, Optical Society of America, Aeronautical and Astronautical Society of the Republic of China, and Phi Tau Phi. 


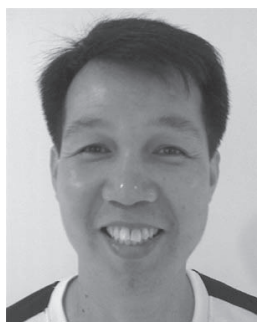

Wen-Tzong (Albert) Shiau received the B.S. degree in mechanical engineering from Tatung Institute of Technology, Taipei, Taiwan, in 1985 and the M.S. degree in mechanical engineering from Auburn University, Auburn, AL, in 1991.

He has been with the National Space Organization (NSPO), Hsinchu, Taiwan, since 1992, where he is a Lead Engineer in the Flight Dynamics Department, Satellite Operation and Control Division. He has two-year experience in satellite attitude determination and control, and thirteen-year experience in orbit flight dynamics analysis. He participated in the development and operations of the flight dynamics facility for FORMOSAT-1, FORMOSAT-2, and FORMOSAT-3 missions in NSPO. He was in charge of the planning and operations of FORMOSAT-2 orbit maneuver from the launch parking orbit to the sun-synchronous mission orbit. His research interests are mainly on the orbit dynamics, particularly the orbit perturbation; orbit maneuver/maintenance; and orbit determination.

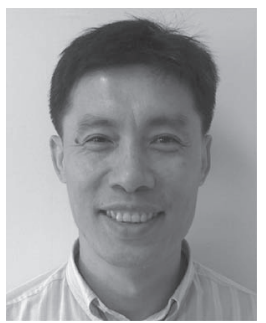

Chen-Tsung (Tom) Lin received the B.S. degree in electrical engineering from the National Taiwan Science and Technology University, Taipei, Taiwan, in 1988 and the M.S. degree in control system engineering from the National Chiao Tung University, Hsinchu, Taiwan, in 1994.

$\mathrm{He}$ is currently with the National Space Organization, Hsinchu, where he is responsible for FORMOSAT-2 and FORMOSAT-3 attitude determination and control subsystem. His current interests include attitude determination, attitude control, engineering development model, hardware-in-the-loop test, and GPS simulation.

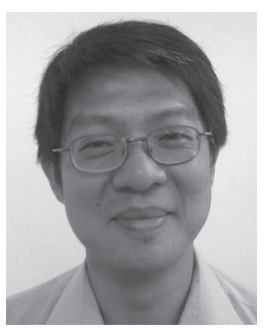

Tien-Chuan Kuo received the B.S., M.S., and Ph.D. degrees in nuclear engineering from the National Tsing Hua University, Hsinchu, Taiwan, in 1988, 1990, and 1996, respectively.

He has been with the National Space Organization (NSPO), Hsinchu, since 1996. He is in charge of the propulsion subsystem of the FORMOSATserious satellite programs, as well as the NSPO interior propulsion development programs, and has 11-year design, analysis, and engineering experience of the spacecraft propulsion system. He has also published 30 journal and conference papers in the areas of satellite propulsion, computational fluid dynamics, Monte Carlo simulations, multiphase flows, phase distribution mechanism, turbulent flow modeling, and particle image velocimetry.

Dr. Kuo is a member of American Institute of Aeronautics and Astronautics, Nanotechnology and Micro System Association (NMA), and Phi-Tau-Phi.

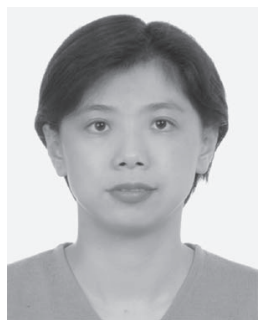

Chung-Huei (Vicky) Chu received the B.S. degree in atmospheric sciences from the National Taiwan University, Taipei, Taiwan, and the M.S. degree in meteorology from Pennsylvania State University, University Park.

She is currently the FORMOSAT-3 Mission Operations Director with the National Space Organization, Hsinchu. She has worked on FORMOSAT series satellite programs since 1994, and she spent one year in the development of science data processing, five years in the flight and ground operations, and six years in mission analysis and system engineering.

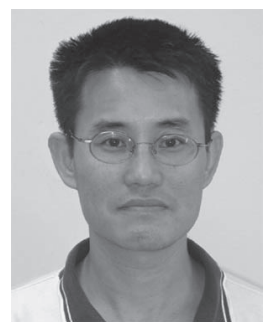

Shan-Kuo (Eddy) Yang received the M.S. degree in engineering science from the National Cheng Kung University, Tainan, Taiwan, in 1987.

He has been with the National Space Organization, Hsinchu, Taiwan, since 1993, where he is currently the Deputy Operation Director of FORMOSAT-3 Mission Operation Team. He was in charge of the end-to-end test between ground and space segments and of the communication infrastructure setup and interphase test between SOCC and the remote ground stations during FORMOSAT-3 integration and test phase. His current interests include GPS radio occultation for the FORMOSAT-3 follow-on mission, satellite simulator, mission planning and scheduling, and long term trending development.

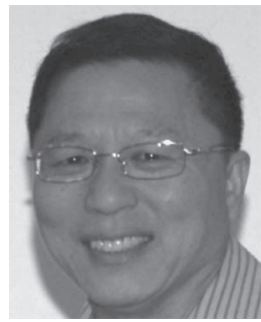

Nick L. Yen received the M.S. degree in mechanical engineering from the Oregon State University, Corvallis, in 1980.

$\mathrm{He}$ is with the National Space Organization, Hsinchu, Taiwan, in 2004 as the Deputy Program Director and soon became the Program Director of FORMOSAT-3/COSMIC Program. He was with the Space Systems/Loral (SS/L), Palo Alto, CA, from 1992 to 2003. He held many key positions in SSL, including SUPERBIRD Senior System Engineer, MBSAT Antenna Subsystem Manager, Control Mechanisms Department Manager, Launch Integration and Launch Operation Department Manager, and Europe* Star Deputy Executive Director. Before that, he was with Ford Aerospace Corporation (former SS/L), Palo Alto, from 1986 to 1992, where he was primarily an Antenna Design Engineer and Antenna Project Manager. Ford Aerospace Corporation was acquired by Loral Corporation and became SS/L in 1992. He was with RCA, East Windsor, NJ, in 1985 as an Antenna Design/Analysis Engineer. He was also with Ford Aerospace Corporation from 1981 to 1984, after the graduate school from Oregon State University, as an Antenna Design/Analysis Engineer. His current research interests include front-to-end process, systems engineering, and FORMOSAT-3 Follow-On constellation mission.

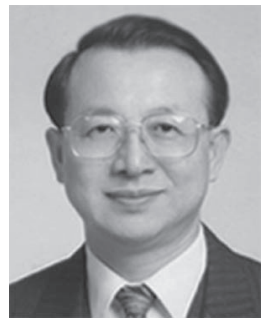

Shao-Shing Chen received the B.E. degree from Chung Cheng Institute of Technology, Tashi, Taiwan, the MBA degree from the National Chengchi University, Taipei, Taiwan, and the Ph.D. degree from the Oklahoma State University, Stillwater.

He has a 30 -year aerospace engineering work experience. He is currently the Deputy Director General with the National Space Organization (NSPO), Hsinchu, Taiwan The FORMOSAT-3/COSMIC program is under his supervision. Prior to NSPO, he was the Deputy Director with the National Precision Instrument Development Center. He was also with Chung-Shan Institute of Science and Technology, Longtan Township, where he served as the Director of the Planning Division, the Section Head of International Cooperation, a QC Engineer, a Reliability Engineer, and QA Planning Officer. He is the author of numerous articles.

Dr. Chen is a member of American Society of Quality Control, Institute of Industrial Engineers, Aeronautical and Astronautical Society of the Republic of China, Chinese Society of Quality Control, Chinese Institute of Industrial Engineers, and Alpha Pi Mu, as well as the adviser of several governmental departments and organizations. He has received a great deal of awards from quality and engineering. 


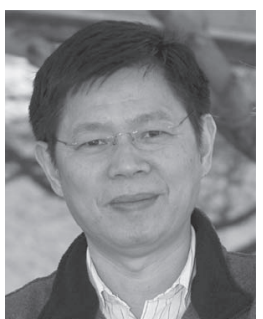

Ying-Hwa Kuo is currently the Director with the COSMIC Program, the University Corporation for Atmospheric Research, Boulder, CO, and the Head of the Mesoscale Prediction Group/Mesoscale and Microscale Meteorology Division, National Center for Atmospheric Research (NCAR), Boulder. He is a recognized leader in the field of mesoscale numerical modeling, meteorological data assimilation, and applications of the GPS radio occultation observation technique. Since 1988, he has served as the NCAR Advisor for over $20 \mathrm{Ph}$.D. students. He has published over 120 journal papers and numerous conference articles and reports. His scientific interests include mesoscale modeling, explosive marine cyclogenesis, mesoscale convective systems, heavy rainfall prediction, data assimilation, GPS/MET research, and model initialization.

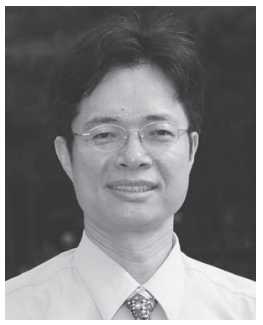

Yuei-An Liou (S'91-M'96-SM'01) received the B.S. degree in electrical engineering from the $\mathrm{Na}-$ tional Sun Yat-Sen University, Kaohsiung, Taiwan, in 1987and the M.S.E. degree in electrical engineering, the M.S. degree in atmospheric and space sciences, and the Ph.D. degree in electrical engineering and atmospheric, oceanic, and space sciences from the University of Michigan, Ann Arbor, in 1992, 1994, and 1996, respectively.

From 1989 to 1990, he was a Research Assistant with the Robotics Laboratory, National Taiwan University, Taipei, Taiwan. From 1991 to 1996, he was a Graduate Student Research Assistant with the Radiation Laboratory, University of Michigan, where he developed land-air interaction and microwave emission models for prairie grassland. He was a Member of the faculty with the Center for Space and Remote Sensing Research (CSRSR), the Institute of Space Sciences, and the Department of Electrical Engineering, National Central University (NCU), Chungli, Taiwan, in 1996, 1997, and 2005, respectively, where he is currently a Professor and the Director of CSRSR. He was the Division Director with the Science Research Division, National Space Organization (NSPO), Hsinchu, Taiwan, in 2005, where he continued to serve as an Advisor in 2006. From August 2006 to July 2007, he was the Chair Professor and the Dean with the College of Electrical Engineering and Computer Science, Ching Yun University, Chungli. His current research activities include GPS meteorology and ionosphere, remote sensing of the atmosphere and land surface, land surface process modeling, and application of neural networks and fuzzy systems in inversion problems. He is a Principal Investigator on many research projects sponsored by the National Science Council (NSC), Council of Agriculture, NSPO, Civil Aeronautics Administration, Ministry of Interior and Water Conservancy Agency of Taiwan, and the Office of Naval Research of USA. He has over 70 referral papers and more than 200 international conference papers. He is a Member of the Editorial Advisory Board of GPS Solutions, and he served as the Guest Editor for the June 2005 Special Issue of "GPS Radio Occultation Experiments" of GPS Solutions. He is a Referee for Terrestrial, Atmospheric and Oceanic Sciences; Asian Journal of Geoinformatics; International Journal of Remote Sensing; Earth, Planets, and Space; Water Resources Research; Environmental Modeling and Software; Remote Sensing of Environment; Journal Geophysical Research; and Annales Geophysicae.

Dr. Liou served as a Leading Guest Editor for the IEEE TRANSACTIONS ON GEOSCIENCE AND REMOTE SENSING (TGRS) special issue "Meteorology, Climate, Ionosphere, Geodesy, and Reflections from the Ocean surfaces: Studies by Radio Occultation Methods." He also serves as the Associate Editor of the IEEE Journal of Selected Topics in Applied Earth Observations and Remote Sensing starting 2008. He is listed in Who's Who in the World. He was a recipient of the Annual Research Awards from NSC in 1998, 1999, and 2000; The First Class Research Awards from NSC in 2004, 2005, and 2006; and the NCU Outstanding Research Awards in 2004 and 2006. He was awarded with "Contribution Award to FORMOSAT3 National Space Mission" by NSPO in 2006. He is a member of the American Geophysical Union, the American Meteorological Society, and the International Association of Hydrological Sciences. He was awarded with Honorary Life Member of The Korean Society of Remote Sensing in 2007. He was elected as a Foreign Member of the Russian Academy of Engineering Sciences in 2008. He was awarded with Outstanding Alumni Award by the University of Michigan Alumni Association in Taiwan in 2008. He is a referee for the IEEE TGRS.

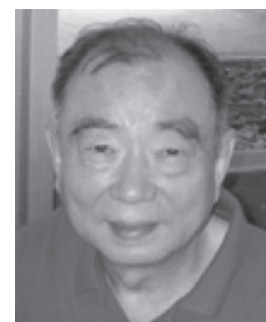

Sien Chi received the B.S.E.E. degree from the National Taiwan University, Taipei, Taiwan, in 1959, the M.S.E.E. degree from the National Chiao Tung University (NCTU), Hsinchu, Taiwan, in 1961, and the Ph.D. degree in electrophysics from the Polytechnic Institute of Brooklyn, Brooklyn, NY, in 1971 .

$\mathrm{He}$ is currently a Professor of electrooptical engineering with the Department of Photonics and Institute of Electro-Optical Engineering, NCTU, where he was the Chair of the Department of Electrophysics from 1972 to 1973 and the Director of the Institute of Electronics from 1973 to 1977 and from 1988 to 1990 . He was the NCTU Vice President from 1998 to 2001. He is also with the Department of Electrical Engineering, Yuan $\mathrm{Ze}$ University, Chungli, Taiwan. From 1977 to 1978, he was a Resident Visitor with Bell Labs, Holmdel, NJ. From 1985 to 1988, he was the Principal Advisor with the Hua-Eng Wires and Cables Company, Kaohsiung, Taiwan. He was the Symposium Chair of the International Symposium of Optoelectronics in Computers, Communications, and Control in 1992, which was coorganized by NCTU and SPIE. Since 1996, he has been the Chair Professor of the Foundation for Advancement of Outstanding Scholarship. His research interests are optical fiber communications, optical solitons, and optical fiber amplifiers.

Dr. Chi received the Distinguished Research Award sponsored by the National Science Council from 1993 to 1996. He is a fellow of Optical Society of America and the Photonics Society of Chinese-Americans. 